\title{
Missing Teeth Predict Incident Cardiovascular Events, Diabetes, and Death
}

\section{Liljestrand, J. M.}

2015-08

Liljestrand, J M , Havulinna, A S , Paju , S, Mannisto , S , Salomaa , V \& Pussinen , P J 2015 , ' Missing Teeth Predict Incident Cardiovascular Events, Diabetes, and Death ' , Journal of Dental Research , vol. 94 , no. 8 , pp. 1055-1062 . https://doi.org/10.1177/0022034515586352

http://hdl.handle.net/10138/157414

https://doi.org/10.1177/0022034515586352

Downloaded from Helda, University of Helsinki institutional repository.

This is an electronic reprint of the original article.

This reprint may differ from the original in pagination and typographic detail.

Please cite the original version. 


\section{Missing Teeth Predict Incident Cardiovascular Events, Diabetes, and Death}

Journal of Dental Research

2015, Vol. 94(8) 1055-1062

(c) International \& American Associations

for Dental Research 2015

Reprints and permissions:

sagepub.com/journalsPermissions.nav

DOI: I0.1 I 77/00220345/5586352

jdr.sagepub.com

\author{
J.M. Liljestrand', A.S. Havulinna ${ }^{2}$, S. Paju', S. Männistö ${ }^{2}$, \\ V. Salomaa ${ }^{2}$, and P.J. Pussinen'
}

\begin{abstract}
Periodontitis, the main cause of tooth loss in the middle-aged and elderly, associates with the risk of atherosclerotic vascular disease. The objective was to study the capability of the number of missing teeth in predicting incident cardiovascular diseases (CVDs), diabetes, and all-cause death. The National FINRISK 1997 Study is a Finnish population-based survey of 8,446 subjects with 13 y of follow-up. Dental status was recorded at baseline in a clinical examination by a trained nurse, and information on incident CVD events, diabetes, and death was obtained via national registers. The registered CVD events included coronary heart disease events, acute myocardial infarction, and stroke. In Cox regression analyses, having $\geq 5$ teeth missing was associated with $60 \%$ to $140 \%$ increased hazard for incident coronary heart disease events $(P<0.020)$ and acute myocardial infarction $(P<0.010)$. Incident CVD $(P<0.043)$, diabetes $(P<0.040)$, and death of any cause $(P<0.019)$ were associated with $\geq 9$ missing teeth. No association with stroke was observed. Adding information on missing teeth to established risk factors improved risk discrimination of death $(P=0.0128)$ and provided a statistically significant net reclassification improvement for all studied end points. Even a few missing teeth may indicate an increased risk of CVD, diabetes, or all-cause mortality. When individual risk factors for chronic diseases are assessed, the number of missing teeth could be a useful additional indicator for general medical practitioners.
\end{abstract}

Keywords: periodontitis, tooth extraction, cardiovascular diseases, partially edentulous jaw, edentulous mouth, diabetes mellitus

\section{Introduction}

Periodontitis is a chronic inflammatory destructive disease in the tooth-supportive tissues - that is, the periodontium. It is a bacterial disease, but the eventual tissue destruction results from an interplay between pathogen activity and a subsequent host response. The association between periodontitis and cardiovascular disease (CVD) has been established, and periodontitis is generally accepted as a CVD risk factor, even though the causality still remains debatable (Desvarieux et al. 2005; Lockhart et al. 2012; Tonetti and Van Dyke 2013). Periodontitis and subsequent systemic inflammation have an additive effect on the development of diabetic complications, probably via exacerbation of insulin resistance (Lalla and Papapanou 2011).

Possible mechanisms explaining the link between periodontitis and systemic chronic diseases includes ongoing lowlevel inflammation and periodontium-originated transient but repeated bacteremia. Inflammation mediators, such as lipopolysaccharide and cytokines, may spread systemically promoting cardiometabolic disorders (Pussinen et al. 2007; Pussinen et al. 2011; Lockhart et al. 2012; Schenkein and Loos 2013; Kallio et al. 2014).

In few prospective studies, tooth loss is independently associated with the risk for incident fatal or nonfatal coronary heart disease (CHD) events (Hung et al. 2004) and diabetes mellitus
(DM; Demmer et al. 2008) as well as CVD-related and allcause mortality (Watt et al. 2012). Thus, we hypothesized that missing teeth reflect an accumulation of oral inflammation to which an individual has experienced throughout his life.

The aim of this study was to investigate the power of missing teeth in predicting incident CVD-namely, CHD events, acute myocardial infarction (AMI), and stroke, as well as incident DM and all-cause death. Our prospective populationbased cohort study utilized $13 \mathrm{y}$ of follow-up data. To our knowledge, this study is the first to assess the association between missing teeth and various incident cardiovascular events with a large population based on a prospective study

\footnotetext{
'Oral and Maxillofacial Diseases, University of Helsinki, Helsinki, Finland ${ }^{2}$ Department of Health, National Institute for Health and Welfare, Helsinki, Finland

A supplemental appendix to this article is published electronically only at http://jdr.sagepub.com/supplemental.

\section{Corresponding Author:}

J.M. Liljestrand, Oral and Maxillofacial Diseases, University of Helsinki, Biomedicum Helsinki I, Haartmaninkatu 8, PO Box 63, FI-000I4 Helsinki, Finland.

Email: john.liljestrand@helsinki.fi
} 
design. Many existing studies assessing this issue are cross sectional, use dichotomized groupings, and utilize diseaserelated mortality rates as the outcome (Ragnarsson et al. 2004; Cabrera et al. 2005; Polzer et al. 2012; Watt et al. 2012).

\section{Materials and Methods}

\section{Baseline}

This study is based on the National FINRISK 1997 Study, a national population-based cohort $(N=8,446)$ with subjects 25 to $74 \mathrm{y}$ of age (Vartiainen et al. 2010). The survey methods follow the World Health Organization's (1988) MONICA protocol. The subjects filled in a comprehensive questionnaire and participated in a clinical examination, which included weight, height, and blood pressure measurements. The cases with existing CVDs or DM at baseline were identified via 1) the questionnaire as a doctor-diagnosed disease ("Has a doctor ever told you that you have diabetes: yes / no"); 2) record linkage with the disease-associated drug reimbursement records from the Social Insurance Institution of Finland, including purchased medications and entitled reimbursements; and 3) record linkage with the National Hospital Discharge register for hospitalizations. In our study, fulfilling any of these identified the subject as having existing CVD or DM. A history of myocardial infarction, revascularizations, or percutaneous transluminal coronary angioplasty was included in CHD events. Previous stroke, excluding subarachnoid hemorrhage, was included in the existing CVD (Kallio et al. 2014).

The number of missing teeth was registered in a clinical examination by a trained nurse. The nurses counted all remaining teeth using a flashlight and a spatula, and they were not especially trained to distinguish natural teeth from, for example, bridge pontics or dental implants. Information on missing teeth was assessed only at baseline, and no follow-up data on tooth loss were available. Presuming that a fully dentate subject has 32 teeth, the population was divided into 5 groups based on the number of missing teeth as follows: 0 to $1(n=$ $2,461), 2$ to $4(n=1,532), 5$ to $8(n=883), 9$ to $31(n=1,813)$, and 32 (edentulous; $n=940$ ). This grouping is designed due to lack of general consensus on appropriate categories of missing teeth. Blood was drawn for laboratory analyses, which were more closely reported earlier (Pussinen et al. 2011). The freetime physical inactivity variable (level 1 on a scale of 1 to 4 ) and parent with DM/AMI variable (if either parent had AMI/ $\mathrm{DM}$ before the age of $60 \mathrm{y}$ ) were obtained from the questionnaire. In a nutrition subsample of the National FINDIET97 ( $n$ $=2,452$ ), information on nutritional intake was collected from the 24-h dietary recall, and we used standard energy densities in the analysis: $37 \mathrm{~kJ} / \mathrm{g}$ for fat, $17 \mathrm{~kJ} / \mathrm{g}$ for protein, and $17 \mathrm{~kJ} / \mathrm{g}$ for carbohydrates (Kallio et al. 2014). All baseline data were collected during 1997. The study was approved by the ethics committee of the National Public Health Institute and conducted according to the Helsinki Declaration. All subjects gave an informed consent. This article is structured according to STROBE guidelines for cohort studies.

\section{Follow-up}

The study includes $>13$ y of follow-up data, with a maximum of $13.9 \mathrm{y}$ and a median of $13.8 \mathrm{y}$ regarding all studied end points. A total of 8,446 subjects participated in the FINRISK97 study. Data on number of teeth was available for 8,142 study participants (Appendix Figure); information on all the covariates was available for 7,862 (total). The methods for diagnosing CVD incidence is thoroughly reported earlier (Pajunen et al. 2004).

The cases with incident CVDs and DM were identified via 1) the drug reimbursement records from the Social Insurance Institution of Finland, 2) the National Hospital Discharge register for hospitalizations, and 3) the National Causes-of-Death Register as the underlying, direct, or contributing cause of death. The last register was also the source of "all-cause mortality" data.

\section{Statistical Analyses}

Statistical analysis was conducted with SPSS 21.0 and R. When the characteristics across the missing-teeth groups were explored, the adjusted $P$ value was calculated with logistic regression analysis and linear trend with 1-way analysis of variance. Due to skewed distributions, triglycerides, C-reactive protein, and gamma-glutamyl transferase were $\log _{10}$-transformed before significance and linear trend tests were analyzed across the missing-teeth groups. To compare the subjects with and without CVD, $P$ values were calculated with Mann-Whitney $U$ and chi-square tests, as appropriate. Missing values regarding parent with DM $(n=689)$ and AMI $(n=691)$ were assumed 0. Subjects with a history of CVD or with DM were excluded from the Cox regression analyses for incident CVD or DM, respectively. Incidences for diseases are reported for a 13-y follow-up, and CVD analyses were adjusted for age, sex, systolic blood pressure, total cholesterol (log), high-density lipoprotein (HDL) cholesterol (log), education (3 categories), smoking (yes/no), treated systolic blood pressure (medication within 0-7 d, yes/no), existing DM, and a geographic variable (east/west). The geographic variable was included because it is an important confounder in our population-based sample (Havulinna et al. 2008). Mortality analyses were additionally adjusted for existing CVD. The adjusted covariates were selected to comply with the current general cardiovascular risk profile presented in the Framingham Heart Study (D'Agostino et al. 2008). DM analysis was adjusted for age, sex, body mass index, smoking (yes/no), physical inactivity, parent with DM, C-reactive protein $(\log )$, and a geographic variable (east/west). These covariates were selected in concordance with an established Diabetes Risk Score (Lindström and Tuomilehto 2003).

The cross-validation subgroup assignment was stratified by sex, 10-y age group, category of missing teeth, and the disease end-point status in question to ensure proper distribution of these important variables in each cross-validation subgroup. We tested the discriminative ability of the models without and with the information on the number of missing teeth using the 
C-index, the net reclassification improvement (NRI), and integrated discrimination improvement statistics for CVD, DM, and death. In analyses for categorical and clinical NRI, the subjects were assigned to 4 groups ( $0 \%$ to $5 \%, 5 \%$ to $10 \%, 10 \%$ to $20 \%,>20 \%)$ and 3 groups $(0 \%$ to $5 \%, 5 \%$ to $20 \%,>20 \%$ ), respectively (Tikkanen et al. 2013). For the 13-y absolute risk predictions, we used $10 \times$ cross validation to reduce overoptimism. The cross validation was stratified by sex, 10 -y age group, disease end-point status, and the category of missing teeth. Cross-validated $(10 \times)$ model calibration was tested using the Hosmer-Lemeshow goodness-of-fit test.

The socioeconomic status was monitored by years of education, which is considered an optimal parameter of the status in Finnish studies (Laatikainen 2000). The education variable with 3 categories is a modification of the standard 3-leveled education variable, which takes into account the subjects' age and sex, thus eliminating the bias caused by changes in the education system. This variable is used in the multiadjusted follow-up analyses. We used the function "cox.zph" in R to assess the validity of Cox proportional hazards assumptions, all of which were met. The assumptions were also assessed graphically with log-minus$\log$ plots and Schoenfeld residuals.

\section{Results}

Number of missing teeth at baseline was associated directly with higher levels of several established CVD risk factors, as shown in Table 1. A significant and linear relationship between a risk factor and missing-teeth group was found for age, education years (inverse), body mass index, HDL cholesterol (inverse), triglycerides, C-reactive protein, male sex, existing DM, and either parent having AMI or DM. Systolic blood pressure, gamma-glutamyl transferase, and cholesterol showed no significant trends due to high standard deviation values. Smokers were equally distributed between among teeth groups, with a group-specific prevalence of $40 \%$ to $48 \%$. Total intake of energy, carbohydrates, proteins, and fat did not differ significantly across missing-teeth categories when adjusted for age, sex, and education years.

We investigated the characteristics of subjects with and without incident CVD and further explored subjects with incident CHD events, AMI, or stroke (Table 2). In sum, 9.9\% of the studied population developed incident CVD in the 13-y followup. All CVD risk factors were significantly different between subjects with and without incident CVD. Presence of DM was 3.5 times more common in subjects having CVD, of which $70 \%$ were men. The risk factors showed similar patterns in the subgroups of CVD (CHD events, AMI, and stroke; data not shown).

Table 3 shows the Cox regression hazard ratios for incident CVD events, DM, and death in the 13-y follow-up for each missing-teeth group, adjusting for covariates. Having 5 to 8 missing teeth increased the hazard for incident CHD events and AMI, which peaked in this category (hazard ratio $=2.39$, $P=0.004)$. The group with 9 to 31 missing teeth provided the largest hazard ratios regarding CHD events and CVDs in general. None of the results for incident stroke were significant.

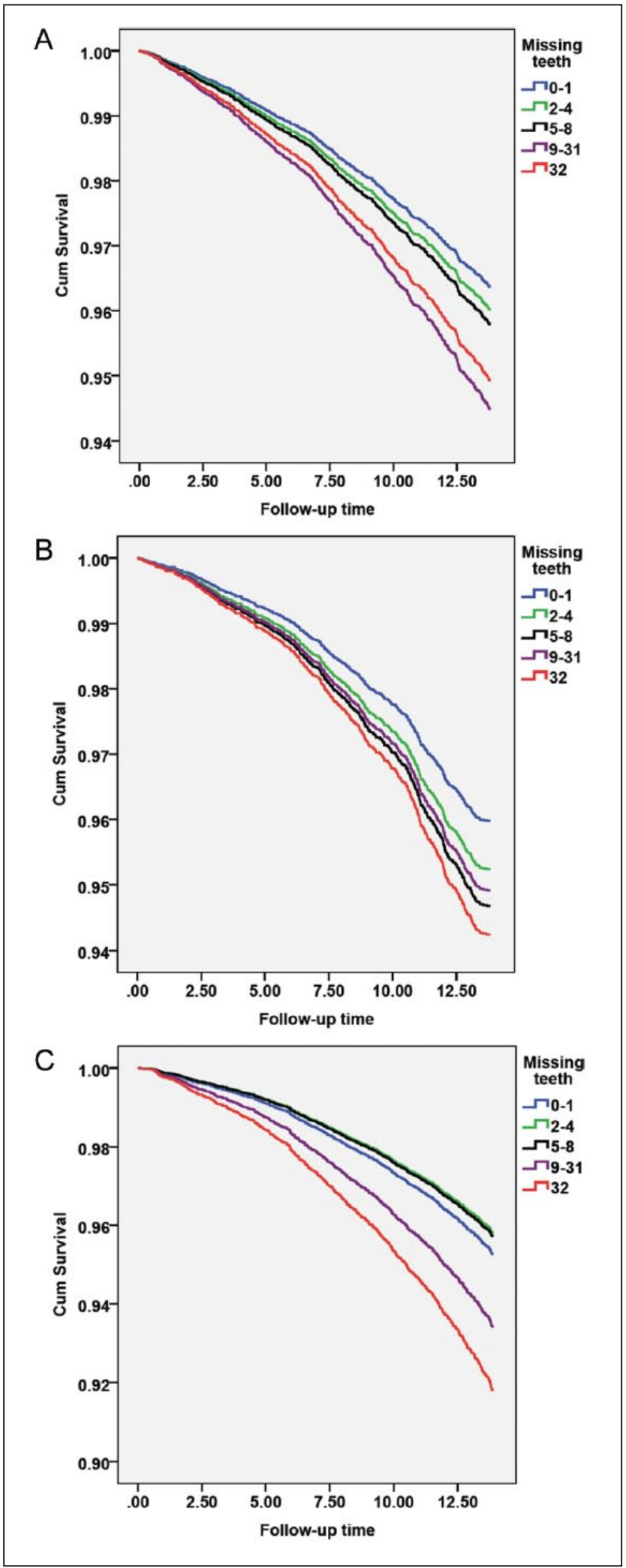

Figure. Cumulative survival plot for incident cardiovascular disease (A), diabetes (B), and all-cause death (C) across the missing-teeth groups in a I3-y follow-up. Cox regression analyses were adjusted for multiple risk factors and the number of missing teeth. 
Table I. Characteristics of Subjects across Missing-Teeth Categories $(N=7,629)$.

\begin{tabular}{|c|c|c|c|c|c|c|}
\hline \multirow[b]{2}{*}{ Risk Factors } & \multicolumn{5}{|c|}{ Missing-Teeth Categories } & \multirow[b]{2}{*}{ Adjusted $P$ Value ${ }^{\mathrm{a}}$} \\
\hline & $0-I(n=2,46 I)$ & $2-4(n=1,532)$ & $5-8(n=883)$ & $9-3 \mid(n=1,8 \mid 3)$ & All $(n=940)$ & \\
\hline Age, y & $38.8 \pm 10.72$ & $45.7 \pm 11.84$ & $51.9 \pm 10.52$ & $56.5 \pm 8.99$ & $60.8 \pm 8.44$ & 0.006 \\
\hline Education y & $13.6 \pm 3.55$ & $12.5 \pm 3.75$ & $11.2 \pm 3.58$ & $9.2 \pm 2.94$ & $7.9 \pm 2.60$ & 0.006 \\
\hline $\mathrm{BMI}, \mathrm{kg} / \mathrm{m}^{2}$ & $25.3 \pm 4.13$ & $26.1 \pm 4.29$ & $26.8 \pm 4.15$ & $28.0 \pm 4.56$ & $28.4 \pm 4.94$ & 0.005 \\
\hline $\mathrm{SBP}, \mathrm{mm} \mathrm{Hg}$ & $128.1 \pm 16.3$ & $132.4 \pm 18.2$ & $137.7 \pm 18.4$ & $143.4 \pm 21.0$ & $|46.2 \pm 2| . \mid$ & 0.071 \\
\hline Total cholesterol, $\mathrm{mmol} / \mathrm{L}$ & $5.22 \pm 1.03$ & $5.47 \pm 1.01$ & $5.70 \pm 1.05$ & $5.82 \pm 1.01$ & $5.91 \pm 1.08$ & 0.445 \\
\hline HDL cholesterol, $\mathrm{mmol} / \mathrm{L}$ & $1.43 \pm 0.36$ & $1.41 \pm 0.36$ & $1.38 \pm 0.36$ & $1.36 \pm 0.37$ & $1.38 \pm 0.36$ & $<0.001$ \\
\hline Triglycerides, $\mathrm{mmol} / \mathrm{L}^{\mathrm{b}}$ & $1.3 \pm 0.94$ & $1.4 \pm 1.07$ & $1.6 \pm 1.04$ & $1.7 \pm 1.08$ & $1.7 \pm 1.01$ & 0.031 \\
\hline CRP, $\mathrm{mg} / \mathrm{L}^{\mathrm{b}}$ & $2.0 \pm 4.44$ & $2.4 \pm 5.67$ & $2.2 \pm 3.59$ & $3.0 \pm 6.07$ & $3.4 \pm 5.90$ & 0.003 \\
\hline $\mathrm{GGT}, \mathrm{U} / \mathrm{L}^{\mathrm{b}}$ & $30.2 \pm 54.6$ & $34.3 \pm 41.2$ & $37.5 \pm 42.2$ & $40.5 \pm 57.6$ & $41.5 \pm 99.2$ & 0.277 \\
\hline Sex, male & $\mathrm{I}, \mathrm{I} 42(46.4)$ & $716(46.7)$ & 467 (52.9) & $\mathrm{I}, 035(57.1)$ & $394(41.9)$ & 0.006 \\
\hline Smoking (ever) & $988(40.1)$ & 730 (47.7) & $42 \mathrm{I}(47.7)$ & $864(47.7)$ & 444 (47.2) & 0.910 \\
\hline Existing DM & $59(2.4)$ & $72(4.7)$ & $55(6.2)$ & $139(7.7)$ & $90(9.6)$ & 0.005 \\
\hline Parent with AMI & $526(21.4)$ & $380(24.8)$ & $273(30.9)$ & $598(33.0)$ & $313(33.3)$ & 0.029 \\
\hline Parent with DM & $466(18.9)$ & $365(23.8)$ & $288(32.6)$ & $634(35.0)$ & $353(37.6)$ & 0.011 \\
\hline Nutritional Intake ${ }^{c}$ & $0-I(n=982)$ & $2-4(n=588)$ & $5-8(n=327)$ & $9-31 \quad(n=638)$ & All $(n=336)$ & \\
\hline Energy, kJ & $8,415 \pm 3,340$ & $7,902 \pm 3,154$ & $7,672 \pm 2,992$ & $8,110 \pm 3,026$ & $7,241 \pm 2,815$ & 0.585 \\
\hline Carbohydrate, E\% & $43.4 \pm 46.8$ & $43.0 \pm 46.1$ & $43.4 \pm 47.0$ & $43.5 \pm 45.1$ & $44.4 \pm 45.8$ & 0.823 \\
\hline Fat, E\% & $33.2 \pm 42.1$ & $33.4 \pm 44.0$ & $33.1 \pm 44.9$ & $33.4 \pm 45.6$ & $32.6 \pm 42.5$ & 0.555 \\
\hline Protein, E\% & $15.2 \pm 17.4$ & $15.3 \pm 16.3$ & $15.5 \pm 17.3$ & $14.9 \pm 17.1$ & $14.9 \pm 19.5$ & 0.053 \\
\hline
\end{tabular}

Values are presented in mean \pm standard deviation or $n(\%)$. Subjects with existing cardiovascular disease at baseline or missing data on number of teeth $(n=817)$ were excluded from the analysis. Linear trend $P$ value for each factor, $P<0.00 I$; linear trend was calculated with $I$-way analysis of variance.

AMI, acute myocardial infarction; BMI, body mass index; CRP, C-reactive protein; DM, diabetes mellitus; E\%, percentage of energy; GGT, gammaglutamyl transferase; SBP, systolic blood pressure.

${ }^{2}$ Adjusted $P$ value was calculated with linear logistic regression model (adjusted for age, sex, and education years); all significant results are displayed in bold.

${ }^{b} P$ values were calculated for the $\log _{10}$-transformed equivalent.

'Data on nutrition was available for a subpopulation $(n=2,452)$.

Table 2. Baseline Characteristics of Subjects without CVD at Baseline by Groups of Incident CVD during I3 y of Follow-up $(N=7,629)$.

\begin{tabular}{|c|c|c|c|c|c|}
\hline \multirow{2}{*}{$\begin{array}{l}\text { CVD Experience during Study: Risk } \\
\text { Factors }\end{array}$} & \multirow{2}{*}{$\begin{array}{l}\text { No Incident CVD } \\
\text { Total }^{a}(n=6,87 \mathrm{I})\end{array}$} & \multicolumn{4}{|c|}{ Type of Incident CVD } \\
\hline & & Total $^{\mathrm{a}}(n=758)$ & $\mathrm{CHD}(n=523)$ & AMI $(n=278)$ & Stroke $(n=293)$ \\
\hline Age, y & $47.2 \pm 12.79$ & $61.1 \pm 9.07$ & $61.1 \pm 8.72$ & $61.8 \pm 8.55$ & $61.8 \pm 9.46$ \\
\hline Education, y & $11.6 \pm 3.91$ & $8.93 \pm 3.71$ & $8.8 \pm 3.58$ & $8.5 \pm 3.17$ & $8.9 \pm 3.82$ \\
\hline $\mathrm{BMI}, \mathrm{kg} / \mathrm{m}^{2}$ & $26.4 \pm 4.52$ & $28.5 \pm 4.31$ & $28.5 \pm 4.03$ & $28.8 \pm 4.13$ & $28.6 \pm 4.64$ \\
\hline $\mathrm{SBP}, \mathrm{mmHg}$ & $134.5 \pm 19.3$ & $149.2 \pm 21.8$ & $148.1 \pm 20.2$ & $149.5 \pm 20.83$ & $150.8 \pm 23.6$ \\
\hline Total cholesterol, $\mathrm{mmol} / \mathrm{L}$ & $5.52 \pm 1.05$ & $5.91 \pm 1.08$ & $5.93 \pm 1.05$ & $5.93 \pm 1.06$ & $5.85 \pm 1.12$ \\
\hline HDL cholesterol, mmol/L & $1.42 \pm 0.36$ & $1.25 \pm 0.33$ & $1.23 \pm 0.32$ & $1.23 \pm 0.34$ & $1.26 \pm 0.32$ \\
\hline Triglycerides, mmol/L & $1.4 \pm 1.02$ & $1.9 \pm 1.10$ & $1.9 \pm 1.07$ & $1.9 \pm 1.09$ & $1.9 \pm 1.15$ \\
\hline $\mathrm{CRP}, \mathrm{mg} / \mathrm{L}$ & $2.4 \pm 5.04$ & $3.8 \pm 7.33$ & $3.9 \pm 7.59$ & $4.5 \pm 9.02$ & $3.7 \pm 5.8$ \\
\hline GGT, U/L & $34.4 \pm 58.4$ & $47.6 \pm 66.2$ & $45.6 \pm 53.0$ & $45.5 \pm 51.8$ & $49.5 \pm 80.2$ \\
\hline Male sex & $3,222(46.9)$ & $532(70.2)$ & $383(73.2)$ & $202(68.8)$ & $196(72.3)$ \\
\hline Ever smoking & $3,069(44.7)$ & 378 (49.9) & $263(50.3)$ & $\mid 43(5 \mid .4)$ & 144 (49.1) \\
\hline Existing DM & $300(4.4)$ & $115(15.2)$ & $80(15.3)$ & $40(14.4)$ & $46(15.7)$ \\
\hline Parent with AMI & I,833 (26.7) & 257 (33.9) & 177 (33.8) & $100(36.0)$ & $98(33.4)$ \\
\hline Parent with DM & I,838 (26.8) & $268(35.4)$ & $188(34.0)$ & $103(37.1)$ & $104(35.5)$ \\
\hline
\end{tabular}

Values are presented in mean \pm standard deviation or $n(\%)$. Subjects with existing CVD at baseline or missing data on number of teeth $(n=8 I 7)$ were excluded from the analysis.

AMI, acute myocardial infarction; BMI, body mass index; CHD, coronary heart disease; CRP, C-reactive protein; CVD, cardiovascular disease; DM, diabetes mellitus; GGT, gamma-glutamyl transferase; SBP, systolic blood pressure.

${ }^{a}$ Comparison between subjects with and without incident CVD, as diagnosed through record linkage with national registers. CHD and stroke are subcategories for CVD, and AMI is a subcategory for CHD. $P$ values were calculated with Mann-Whitney $U$ tests for continuous variables and chisquare tests for categorical variables; all values were significant $(P<0.05)$. The numbers of participants in the 3 columns $(C H D, A M I$, and Stroke) do not add up to 758, because several participants experienced events in multiple incident CVD categories. 
Table 3. Association of Missing Teeth with Incident CVD Events, DM, and Death in a Follow-up of I3 y.

\begin{tabular}{|c|c|c|c|c|c|c|}
\hline $\begin{array}{l}\text { No. of Missing Teeth, } \\
\text { Baseline }\end{array}$ & CVD $(n=692)$ & $\mathrm{CHD}(n=482)$ & AMI $(n=253)$ & Stroke $(n=268)$ & Death $(n=89 I)$ & $\mathrm{DM}(n=557)$ \\
\hline $0-I, H R$ & $1.00^{\mathrm{a}}$ & $1.00^{\mathrm{a}}$ & $1.00^{\mathrm{a}}$ & $1.00^{\mathrm{a}}$ & $1.00^{\mathrm{b}}$ & $1.00^{c}$ \\
\hline \multicolumn{7}{|l|}{$2-4$} \\
\hline $\mathrm{HR}$ & 1.10 & 1.22 & $\mathrm{I} .4 \mathrm{I}$ & 0.95 & 0.88 & 1.20 \\
\hline $95 \% \mathrm{Cl}$ & $0.80-|.5|$ & $0.81-1.85$ & $0.76-2.63$ & $0.59-1.54$ & $0.66-1.19$ & $0.88-1.63$ \\
\hline$P$ value & $0.57 \mid$ & 0.339 & 0.280 & 0.837 & 0.418 & 0.258 \\
\hline \multicolumn{7}{|l|}{$5-8$} \\
\hline $\mathrm{HR}$ & 1.18 & 1.62 & 2.39 & 0.61 & 0.90 & 1.36 \\
\hline $95 \% \mathrm{Cl}$ & $0.85-1.63$ & $1.08-2.43$ & $|.32-4.3|$ & $0.35-1.06$ & $0.66-1.24$ & $0.97-1.90$ \\
\hline$P$ value & 0.331 & 0.020 & 0.004 & 0.078 & 0.530 & 0.071 \\
\hline \multicolumn{7}{|l|}{$9-31$} \\
\hline $\mathrm{HR}$ & I.5I & 1.99 & 2.10 & 1.05 & 1.37 & 1.37 \\
\hline $95 \% \mathrm{Cl}$ & $1.13-2.02$ & $1.37-2.89$ & $|| 9-3.7 \mid$. & $0.67-1.65$ & I.05-I.79 & $1.02-1.86$ \\
\hline$P$ value & 0.006 & $<0.001$ & 0.010 & 0.819 & 0.019 & 0.040 \\
\hline \multicolumn{7}{|l|}{32 (edentulous) } \\
\hline $\mathrm{HR}$ & 1.40 & 1.65 & 1.84 & 1.17 & 1.68 & 1.56 \\
\hline $95 \% \mathrm{Cl}$ & $1.01-1.95$ & $1.09-2.50$ & $0.99-3.42$ & $0.71-1.92$ & $1.26-2.24$ & $1.10-2.20$ \\
\hline$P$ value & 0.043 & 0.018 & 0.052 & 0.534 & $<0.001$ & 0.012 \\
\hline
\end{tabular}

Bold indicates statistical significance. CHD and stroke are subcategories for CVD, and AMI is a subcategory for CHD. Cox regression analyses were adjusted for age, sex, smoking (yes/no), and a geographic variable (east/west).

$\mathrm{AMI}$, acute myocardial infarction; $\mathrm{CHD}$, coronary heart disease; $\mathrm{Cl}$, confidence interval; $\mathrm{CVD}$, cardiovascular disease; DM, diabetes mellitus; HR, hazard ratio.

${ }^{\mathrm{a}}$ Total $n=7,397$ free from CVD at baseline, additionally adjusted for systolic blood pressure, blood pressure treatment (medication within 0 and $7 \mathrm{~d}$, yes/no), total cholesterol (log), HDL cholesterol (log), education (3 categories), and existing DM.

${ }^{6}$ Total $n=7,862$, additionally adjusted for existing CVD.

${ }^{\mathrm{C}}$ Total $n=7,198$ without DM at baseline, additionally adjusted for body mass index, physical inactivity, parent with DM, and C-reactive protein (log).

Fully edentulous subjects had smaller hazard ratios for incident CVD and CHD events than did those in the group with 9 to 31 missing teeth. However, edentulous subjects- had the largest hazard ratios for DM and death. The survival plots for CVDs, $\mathrm{DM}$, and death across missing-teeth groups are presented in the Figure.

The discrimination and reclassification of individuals after addition of missing-teeth groups to established risk profiles for incident CVD events, DM, and death stratified by $10-\mathrm{y}$ age groups are shown in Table 4 . The clinical NRI was significantly positive for all end points investigated using Cox regression models with age as the time scale. The clinical NRI was calculated with reclassification among those participants who were classified to the intermediate risk group (5\% to $20 \%$ ) by the model using only established risk factors. The difference in c-statistics was statistically significant regarding all-cause mortality $(0.0027, P=0.0100)$. All models were properly calibrated for absolute prediction (Hosmer-Lemeshow test, $P>0.05$ ).

\section{Discussion}

In this prospective cohort study of a population-based sample of Finnish adults, we show that the number of missing teeth at baseline associates with incident CVD, CHD events, AMI, $\mathrm{DM}$, and death after adjustment for covariates. The presented hazards for CVD and DM are adjusted for selected covariates, which comply with the current Framingham general cardiovascular risk profile and the Diabetes Risk Score, respectively (Lindström and Tuomilehto 2003; D’Agostino et al. 2008).
Adding information of missing teeth to the traditional risk profile moderately improved the cross-validated risk prediction regarding all-cause mortality.

Our main hypothesis is that advanced tooth loss somewhat reflects a past accumulation of oral inflammation, and it appears that missing teeth may be a contributing factor in determining cardiovascular risk. The 2 foremost reasons for loss of teeth are caries and periodontitis. Caries has been reported as the main cause for tooth extractions in the British adult population and generally as the main cause at the individual level, while periodontitis has been proposed to be the leading cause for tooth extractions at the tooth level (Phipps and Stevens 1995; Richards et al. 2005). Periodontitis has been claimed to be the world's most common cause for extracting teeth in subjects $>40$ y of age (Reich and Hiller 1993; Phipps and Stevens 1995; Agerholm 2001; Gomes et al. 2012). Missing teeth has been proposed as a surrogate marker for periodontitis (Desvarieux et al. 2003; Holmlund and Lind 2012), and it is easily accessible information compared to diagnosis of periodontitis, which relies on clinical examinations and radiographic analysis by a dentist. A comprehensive review by Polzer et al. (2012) and large prospective cohort studies by Watt et al. (2012) and Schwahn et al. (2013) suggested causation between missing teeth and circulatory mortality, while allcause mortality still lacks sufficient evidence. Recently, Wiener and Sambamoorthi (2014) concluded a significant independent association between self-reported missing teeth values and CVD in a rather large $(N=275,424)$ cross-sectional study setup. Also Cabrera et al. (2005) found an association between 
Table 4. Discrimination and Reclassification for I3-y CVD Events, DM, and Death in the Established Risk Profiles: Groups with and without Missing Teeth.

\begin{tabular}{|c|c|c|c|c|c|c|}
\hline \multirow[b]{2}{*}{ End Point } & \multicolumn{3}{|c|}{ C-statistic } & \multicolumn{3}{|c|}{ Improvement } \\
\hline & $\begin{array}{l}\text { Reference Risk } \\
\text { Score }^{\mathrm{a}}\end{array}$ & $\begin{array}{l}\text { Extended Risk } \\
\text { Score }^{\mathrm{b}}\end{array}$ & Difference & $\begin{array}{c}\text { Integrated } \\
\text { Discrimination }\end{array}$ & $\begin{array}{l}\text { Categorical Net } \\
\text { Reclassification }\end{array}$ & $\begin{array}{c}\text { Clinical Net } \\
\text { Reclassification }\end{array}$ \\
\hline$C D^{c}$ & 0.8365 & 0.8369 & $0.0004 \pm 0.0007$ & $0.0020 \pm 0.0009$ & $-0.008 \pm 0.011$ & $0.067 \pm 0.019$ \\
\hline$P$ value & & & 0.547 & 0.0205 & 0.470 & $<0.001$ \\
\hline Death $^{d}$ & 0.8264 & 0.8291 & $0.0027 \pm 0.0010$ & $0.007 I \pm 0.0015$ & $0.024 \pm 0.004$ & $0.074 \pm 0.021$ \\
\hline$P$ value & & & 0.010 & $<0.001$ & 0.0365 & $<0.00 \mathrm{I}$ \\
\hline $\mathrm{DM}^{\mathrm{e}}$ & 0.8265 & 0.8266 & $0.0001 \pm 0.0008$ & $0.0010 \pm 0.0008$ & $0.012 \pm 0.010$ & $0.050 \pm 0.011$ \\
\hline$P$ value & & & 0.879 & 0.189 & 0.2339 & $<0.001$ \\
\hline
\end{tabular}

The Cox regression reference risk model included age (as the time scale), sex, smoking (yes/no), and a geographic variable (east/west). Bold indicates statistical significance.

BMI, body mass index; CVD, cardiovascular disease; DM, diabetes mellitus; NRI, net reclassification improvement.

${ }^{\text {a }}$ Framingham risk factors only.

${ }^{\mathrm{b}}$ Number of missing teeth added.

'Total $n=7,397, n=692$, additionally adjusted for systolic blood pressure, blood pressure treatment (medication within 0-7 days, yes / no), total cholesterol (log), HDL cholesterol (log), education (three categories) and existing DM.

${ }^{\mathrm{d}}$ Total $n=7,862, n=891$, additionally adjusted for existing CVD.

${ }^{\mathrm{e}}$ Total $n=7,198, n=557$. Additionally adjusted for BMI, BMI/age, physical inactivity, parent with DM, and C-reactive protein (log). The risk prediction model was extended with missing-teeth groups (0-2, 3-4, 5-8, 9-31, 32 missing). Categorical NRI was assessed for 4 risk categories (0-5\%, 5-10\%, $10-20 \%,>20 \%$ ) and clinical NRI- that is, reclassification from $5 \%$ to $20 \%$ predicted risk by the traditional model into 3 risk categories $(0-5 \%, 5-20 \%$, $>20 \%$ ). For the $13-y$ absolute risk predictions, we used $10 x$ cross validation stratified by sex, 10-y age group, disease end-point status, and the category of missing teeth.

missing teeth and all-cause mortality among 1,462 studied women with 24 y of follow-up. Our study further strengthens this evidence, especially since adding information on missing teeth to established risk factors significantly improved the risk discrimination of death.

Tooth loss or missing teeth have been used as a marker of past and present periodontal status in a large number of crosssectional studies concerning CVD. The studies that measure the association between missing teeth and signs of CVD — such as coronary atherosclerotic burden with coronary angiography, carotid ultrasound, arterial stiffness, or self-reported angina pectoris-support our results (Desvarieux et al. 2003; Desvarieux et al. 2005; Gomes et al. 2012; Holmlund and Lind 2012; Medina-Solis et al. 2014; Asai et al. 2015). Presently, we analyzed the association between missing teeth and various incident cardiovascular events, while most studies have used mortality rates as the outcome (Ragnarsson et al. 2004; Cabrera et al. 2005; Polzer et al. 2012; Watt et al. 2012). Record linkage through national registers has proven to be a reasonably valid indicator for detecting incident CHD events (Pajunen et al. 2005).

Some of the earlier studies use self-reported values for missing teeth (Holmlund and Lind 2012; Medina-Solis et al. 2014; Wiener and Sambamoorthi 2014). In earlier reports, study groups have been typically dichotomized - for example, into dentate/edentate or having $<10$ or $<20$ teeth; alternatively, they have used the number of teeth as a continuous variable (Polzer et al. 2012). In this study, we used the division into missing-teeth groups due to lack of general consensus. Of course, the causes of missing teeth overlap across groups, but hypothetical cause grouping may aid in the interpretation of results: The first group, with 0 to 1 missing teeth, represents periodontally healthy subjects (controls); the group with 2 to 4 missing teeth is likely explained by lack of or extractions of third molars; those missing 5 to 8 teeth may have additionally lost them due to orthodontic reasons, periodontitis, or caries (Phipps and Stevens 1995; Gomes et al. 2012); and those with 9 to 31 missing teeth most likely suffer from chronic periodontitis. The 2 groups with most missing teeth may represent ongoing or treated advanced oral disease with plausible systemic inflammatory burden. It is noteworthy that tooth extraction practices might vary internationally. Thus, missing teeth might not relate to periodontitis similarly in all populations. Missing teeth is a somewhat difficult epidemiologic biomarker because it could reflect severe disease, treated periodontitis, or both (Cabrera et al. 2005). Edentulousness represents an unusual end stage of the disease, eliminating all clinical evidence of ongoing inflammation, even though the systemic damage may be irreversible and evident (Hujoel et al. 2001).

We observed a peak in the AMI incidence in the group with 5 to 8 missing teeth, and a CVD incidence peak in the group with 9 to 31 missing teeth at baseline. Due to the magnitude of tooth loss, we hypothesize that these subjects suffer from chronic periodontitis. This hypothesis and curvilinear association are supported by earlier findings (Desvarieux et al. 2003; Pussinen et al. 2003). The subjects with few remaining teeth may have attenuated mastication, which could lead to unhealthier nutritional intake (Geissler et al. 1984; Schwahn et al. 2013). However, no significant difference in nutritional intake was observed across missing-teeth groups in the subpopulation of the present study after adjusting for age, sex, and education years. Interestingly, edentulous subjects had the largest hazards for all-cause death and DM but not for CVD. This finding challenges the proposed dose-response relationship and shifts the 
attention toward existing compromised dentition (Holmlund and Lind 2012).

The link between periodontitis and DM may be bidirectional (Lalla and Papapanou 2011). The severity of periodontitis seems to worsen glycemic control via induction of systemic inflammation (Taylor et al. 1996). DM impairs repair of periodontitis-induced tissue destruction and may lead to a hyperinflammatory response to the pathogen load (Lalla and Papapanou 2011). Limited information is available on incident DM of individuals without DM at baseline (Demmer et al. 2008; Ide et al. 2011). Demmer et al. (2008) showed in the NHANES I, with $17 \mathrm{y}$ of mean follow-up, that the 3 highest quintiles of periodontitis severity were associated with the risk of DM. In dentate individuals, advanced tooth loss (25 to 31 missing teeth) was associated with incident DM when compared to those with 0 to 8 missing teeth (odds ratio $=1.70, P<$ 0.05 ). The hazards in our study were in the same level, but the increased risk was obvious already with $\geq 5$ missing teeth.

The strengths of this study are a large population, long and complete follow-up, and known risk factors for multivariate adjustments. The most important limitation is lack of reasons or diagnosis for tooth extractions. Data on eventual prosthodontics or position of remaining teeth, which would have given insight into the masticatory ability, were not available. Also, no follow-up data on missing teeth were available. We did not separate ischemic from hemorrhagic strokes, which would have been beneficial due to the different etiologies of these subtypes. Residual confounding is present because tooth loss is likely to be correlated with various lifestyle and behavioral factors that affect health outcomes. The 24-h dietary recall is not an optimal way of measuring individual nutritional intake. Misclassification is possible in recording of missing teeth due to fixed prosthodontics or residual roots. Finally, our study setup is not suited to explore causality between missing teeth and the end points, merely associations.

\section{Conclusions}

The associations between oral diseases and general health have lately attracted attention, and the World Health Organization has acknowledged oral health care's importance in preventing fatal chronic diseases (Petersen and Yamamoto 2005). The number of missing teeth, which has been proposed as a surrogate marker for current or past periodontitis, may indicate an increased risk for CVD, DM, and all-cause mortality, and it could be added into existing cardiovascular risk profiles as an additional risk factor. In the light of these findings and the relative ease in counting natural teeth, the number of missing teeth could be a useful indicator for general medical practitioners to refer their patients for further medical evaluation.

\section{Author Contributions}

J.M. Liljestrand, contributed to conception, design, data analysis, and interpretation, drafted the manuscript; A.S. Havulinna, P.J. Pussinen, contributed to conception, design, data analysis, and interpretation, critically revised the manuscript; S. Paju, V. Salomaa, contributed to conception, design, and data interpretation, critically revised the manuscript; S. Männistö, contributed to data interpretation, critically revised the manuscript. All authors gave final approval and agree to be accountable for all aspects of the work.

\section{Acknowledgments}

The study was supported by the Academy of Finland (1266053; P.J.P.), the Sigrid Juselius Foundation (P.J.P.), the Finnish Foundation for Cardiovascular Research (V.S.), and Odontologiska Samfundet i Finland r.f. (J.M.L.). The authors declare no potential conflicts of interest with respect to the authorship and/or publication of this article.

\section{References}

Agerholm D. 2001. Reasons for extraction by dental practitioners in England and Wales: a comparison with 1986 and variations between regions. J Dent. 29(4):237-241.

Asai K, Yamori M, Yamazaki T, Yamaguchi A, Takahashi K, Sekine A, Kosugi S, Matsuda F, Nakayama T, Bessho K. 2015. Tooth loss and atherosclerosis: the Nagahama Study. J Dent Res. 94(3):52S-58S.

Cabrera C, Hakeberg M, Ahlqwist M, Wedel H, Bjorkelund C, Bengtsson C, Lissner L. 2005. Can the relation between tooth loss and chronic disease be explained by socio-economic status? A 24-year follow-up from the population study of women in Gothenburg, Sweden. Eur J Epidemiol. 20(3):229-236.

D’Agostino RBS, Vasan RS, Pencina MJ, Wolf PA, Cobain M, Massaro JM, Kannel WB. 2008. General cardiovascular risk profile for use in primary care: the Framingham Heart Study. Circulation. 117(6):743-753.

Demmer RT, Jacobs DR Jr, Desvarieux M. 2008. Periodontal disease and incident type 2 diabetes: results from the first national health and nutrition examination survey and its epidemiologic follow-up study. Diabetes Care. 31(7):1373-1379.

Desvarieux M, Demmer RT, Rundek T, Boden-Albala B, Jacobs DR Jr, Papapanou PN, Sacco RL; Oral Infections and Vascular Disease Epidemiology Study. 2003. Relationship between periodontal disease, tooth loss, and carotid artery plaque: the Oral Infections and Vascular Disease Epidemiology Study (INVEST). Stroke. 34(9):2120-2125.

Desvarieux M, Demmer RT, Rundek T, Boden-Albala B, Jacobs DR Jr, Sacco RL, Papapanou PN. 2005. Periodontal microbiota and carotid intima-media thickness: the Oral Infections and Vascular Disease Epidemiology Study (INVEST). Circulation. 111(5):576-582.

Geissler CA, Bates JF. 1984. The nutritional effects of tooth loss. Am J Clin Nutr. 39(3):478-489.

Gomes MS, Chagas P, Padilha DM, Caramori P, Hugo FN, Schwanke CH, Hilgert JB. 2012. Association between self-reported oral health, tooth loss and atherosclerotic burden. Braz Oral Res. 26(5):436-442.

Havulinna AS, Pääkkönen R, Karvonen M, Salomaa V. 2008. Geographic patterns of incidence of ischemic stroke and acute myocardial infarction in Finland during 1991-2003. Ann Epidemiol. 18(3):206-213.

Holmlund A, Lind L. 2012. Number of teeth is related to atherosclerotic plaque in the carotid arteries in an elderly population. J Periodontol. 83(3):287-291.

Hujoel PP, Drangsholt M, Spiekerman C, Derouen TA. 2001. Examining the link between coronary heart disease and the elimination of chronic dental infections. J Am Dent Assoc. 132(7):883-889.

Hung HC, Joshipura KJ, Colditz G, Manson JE, Rimm EB, Speizer FE, Willett WC. 2004. The association between tooth loss and coronary heart disease in men and women. J Public Health Dent. 64(4):209-215.

Ide R, Hoshuyama T, Wilson D, Takahashi K, Higashi T. 2011. Periodontal disease and incident diabetes: a seven-year study. J Dent Res. 90(1):41-46.

Kallio KA, Hätönen KA, Lehto M, Salomaa V, Männistö S, Pussinen PJ. 2014. Endotoxemia, nutrition, and cardiometabolic disorders. Acta Diabetol. 52(2):395-404.

Laatikainen T. 2000. Cardiovascular risk in the Republic of Karelia, Russia comparison of major risk factors with North Karelia, Finland. Helsinki (Finland): National Public Health Institute.

Lalla E, Papapanou PN. 2011. Diabetes mellitus and periodontitis: a tale of two common interrelated diseases. Nat Rev Endocrinol. 7(12):738-748.

Lindström J, Tuomilehto J. 2003. The diabetes risk score: a practical tool to predict type 2 diabetes risk. Diabetes Care. 26(3):725-731.

Lockhart PB, Bolger AF, Papapanou PN, Osinbowale O, Trevisan M, Levison ME, Taubert KA, Newburger JW, Gornik HL, Gewitz MH. 2012. Periodontal disease and atherosclerotic vascular disease: does the evidence support an 
independent association? A scientific statement from the American Heart Association. Circulation. 125(20):2520-2544.

Medina-Solis CE, Pontigo-Loyola AP, Perez-Campos E, Hernandez-Cruz P, Avila-Burgos L, Kowolik MJ, Maupome G. 2014. Association between edentulism and angina pectoris in Mexican adults 35 years of age and older: a multivariate analysis of a population-based survey. J Periodontol. 85(3):406-416

Pajunen P, Koukkunen H, Ketonen M, Jerkkola T, Immonen-Räihä P, KärjäKoskenkari P, Mähönen M, Niemelä M, Kuulasmaa K, Palomäki P, et al. 2005. The validity of the Finnish Hospital Discharge Register and Causes of Death Register data on coronary heart disease. Eur J Cardiovasc Prev Rehabil. 12(2):132-137.

Pajunen P, Pääkkönen R, Juolevi A, Hämäläinen H, Keskimäki I, Laatikainen T, Moltchanov V, Niemi M, Rintanen H, Salomaa V. 2004. Trends in fatal and non-fatal coronary heart disease events in Finland during 1991-2001. Scand Cardiovasc J. 38(6):340-344.

Petersen PE, Yamamoto T. 2005. Improving the oral health of older people: the approach of the WHO Global Oral Health Programme. Community Dent Oral Epidemiol. 33(2):81-92.

Phipps KR, Stevens VJ. 1995. Relative contribution of caries and periodontal disease in adult tooth loss for an HMO dental population. J Public Health Dent. 55(4):250-252.

Polzer I, Schwahn C, Volzke H, Mundt T, Biffar R. 2012. The association of tooth loss with all-cause and circulatory mortality: is there a benefit of replaced teeth? A systematic review and meta-analysis. Clin Oral Investig. 16(2):333-351.

Pussinen PJ, Jousilahti P, Alfthan G, Palosuo T, Asikainen S, Salomaa V. 2003. Antibodies to periodontal pathogens are associated with coronary heart disease. Arterioscler Thromb Vasc Biol. 23(7):1250-1254

Pussinen PJ, Havulinna AS, Lehto M, Sundvall J, Salomaa V. 2011. Endotoxemia is associated with an increased risk of incident diabetes. Diabetes Care. 34(2):392-397.

Pussinen PJ, Tuomisto K, Jousilahti P, Havulinna AS, Sundvall J, Salomaa V. 2007. Endotoxemia, immune response to periodontal pathogens, and systemic inflammation associate with incident cardiovascular disease events. Arterioscler Thromb Vasc Biol. 27(6):1433-1439.
Ragnarsson E, Eliasson ST, Gudnason V. 2004. Loss of teeth and coronary heart disease. Int J Prosthodont. 17(4):441-446.

Reich E, Hiller KA. 1993. Reasons for tooth extraction in the western states of Germany. Community Dent Oral Epidemiol. 21(6):379-383.

Richards W, Ameen J, Coll AM, Higgs G. 2005. Reasons for tooth extraction in four general dental practices in South Wales. Br Dent J. 198(5):275-278.

Schenkein HA, Loos BG. 2013. Inflammatory mechanisms linking periodontal diseases to cardiovascular diseases. J Periodontol. 84(4):S51-S69.

Schwahn C, Polzer I, Haring R, Dörr M, Wallaschofski H, Kocher T, Mundt T, Holtfreter B, Samietz S, Völzke H, et al. 2013. Missing, unreplaced teeth and risk of all-cause and cardiovascular mortality. Int J Cardiol. 167(4):1430-1437.

Taylor GW, Burt BA, Becker MP, Genco RJ, Shlossman M, Knowler WC, Pettitt DJ. 1996. Severe periodontitis and risk for poor glycemic control in patients with non-insulin-dependent diabetes mellitus. J Periodontol. 67(10 Suppl): $1085-1093$.

Tikkanen E, Havulinna AS, Palotie A, Salomaa V, Ripatti S. 2013. Genetic risk prediction and a 2-stage risk screening strategy for coronary heart disease. Arterioscler Thromb Vasc Biol. 33(9):2261-2266.

Tonetti MS, Van Dyke TE. 2013. Periodontitis and atherosclerotic cardiovascular disease: consensus report of the Joint EFP/AAP Workshop on Periodontitis and Systemic Diseases. J Clin Periodontol. 40 Suppl 14:S24 S29.

Vartiainen E, Laatikainen T, Peltonen M, Juolevi A, Männistö S, Sundvall J, Jousilahti P, Salomaa V, Valsta L, Puska P. 2010. Thirty-five-year trends in cardiovascular risk factors in Finland. Int J Epidemiol. 39(2):504-518.

Watt RG, Tsakos G, de Oliveira C, Hamer M. 2012. Tooth loss and cardiovascular disease mortality risk: results from the Scottish health survey. PLoS One. 7(2):e30797.

Wiener RC, Sambamoorthi U. 2014. Cross-sectional association between the number of missing teeth and cardiovascular disease among adults aged 50 or older: BRFSS 2010. Int J Vasc Med. 2014:421567.

World Health Organization. 1988. The World Health Organization MONICA Project (monitoring trends and determinants in cardiovascular disease): a major international collaboration. WHO MONICA Project Principal Investigators. J Clin Epidemiol. 41(2):105-114. 